\title{
The role of the social community networks in the care of chronic wounds
}

\author{
Isabella Lo Castro
}

Psychologist psychotherapist, Department of Military Psychology of the Italian Army General Staff, Contravulnera Onlus, Italy

\section{ABSTRACT}

The aim of this article is to suggest a multidisciplinary approach to the clinical practice of treating patients with chronic wounds $(C W)$. It will take into consideration and further investigate the relational and community dimensions of patients and his/her caregivers, as these affect the very quality of life and healing process. Scientific literature and clinical experience underline that taking family, friend, professional and community networks of patients into consideration may represent either a strengthening or weakening factor that improves/undermines the improvement of the patients 'psychological and physical conditions. Based on some of well-known reference, a systemic-relational interpretation has been applied to the Chronic Care Model used on patients with CW; in particular, Carlos Sluzki's theoretical and operational concept based on the idea of social network was used. Approaching clinical practice by considering the patients' psychosocial and community aspects and their social network has positive effects on the quality of life and leverages the healing process, also through therapeutic and intervention choices of the caring team that encourage compliance.

\section{INTRODUCTION}

In recent decades, the clinical experience and scientific studies have underlined the importance of psychosocial factors in the healing process of chronic wounds $(\mathrm{CW})$. Although the present research to understand the details of how these factors work is still limited, we know that some elements, such as past experience, special living conditions, expectations, and personal values influence the psychological response of patients and their ability to deal with the complex situation they face.

Correspondence: Isabella Lo Castro, Stato Maggiore dell'Esercito - Ufficio di Psicologia Militare, Contravulnera Onlus, Via G. Molino Colombini, 3000135 Rome, Italy.

Tel.: +39.3476960923

E-mail: isabella.locastro@libero.it

Key words: Chronic wounds, chronic care model, forever healing, quality of life, social networks.

Conflict of interest: the author declares no potential conflict of interest.

Received for publication: 15 May 2017.

Revision received: 15 May 2017.

Accepted for publication: 12 February 2018.

This work is licensed under a Creative Commons Attribution NonCommercial 4.0 License (CC BY-NC 4.0).

(C) Copyright I. Lo Castro, 2017

Licensee PAGEPress, Italy

Italian Journal of Wound Care 2017; 1(2):52-55

doi:10.4081/ijwc.2017.10

\section{PSYCHOSOCIAL FACTORS AND HEALTH-RELATED QUALITY OF LIFE IN TREATING CHRONIC WOUNDS}

The above mentioned interconnected factors can influence chronicity and cause healing delays: the impact of psychosocial factors on the quality of life is far-reaching and often prevailing on the management of an open wound. In their well-known phenomenological study published in the Journal of Vascular Nursing, Chase et al. ${ }^{1}$ studied 38 patients with leg ulcers for more than one year. Their methodology included weekly measurements of wound size, pain measurement, review of the medical records, consideration of any other condition and emergency/planned admission to hospital. During treatment until recovery, they resorted to participant observation of patients during visits and interviews, which were transcribed and analysed individually. Four main themes emerged from the analysis that the authors summarized in four short sentences, notably: i) healing process forever, i.e. the extended time during which healing occurs; ii) limits and accommodations, i.e. the restriction of activities due to pain and disfigurement; iii) powerlessness, i.e. the feeling of resignation due to inevitability of wound relapse; iv) who cares?, i.e. the differences among patients in taking responsibility for the management of their injury.

In particular, the first, known as healing forever, provides an accurate description of this long process. The authors point out that understanding disease as unavoidable and chronic experience, helps caregivers to provide care empathetically and encourage patients. In fact, the latter may, to different degrees, not feel responsible for their situation, or rather feel they are active members of the caring 
team up to choosing to take the burden of care and lifestyle choices onto their shoulders.

More recently, Van Korlaar et al. ${ }^{2}$ showed also that $\mathrm{CW}$ are associated with a severe deficit in Health-Related Quality of Life. Similarly, several studies of patients with leg ulcers, diabetic foot and pressure wounds have shown that they - while accepting ulcers as part of their lives continue to fight against social exclusion that results from their condition. . $^{3,4}$

The position paper of the European Wound Management Association (EWMA) $)^{5}$ summarizes the psychosocial factors associated with the duration or chronicity of healing that has more frequently been cited in the literature. These are: i) Socio-economic status; ii) Social isolation; iii) Psychosocial impact of wound-related symptoms; iv) Health care worker skills.

In particular, among what we can call psycho-social and relational symptoms, sleep disorders, anxiety and depression, presence of exudate and odour, and the subsequent lifestyle, are among the more frequent and negatively affecting the patients' lives.

\section{SOCIAL NETWORK AND THE HEALING PROCESS IN THE TREATMENT OF CHRONIC WOUNDS}

This paragraph is about the role of the social network and community with respect to the first three psychosocial factors mentioned above and the importance of their effect on patient healing.

Based on Argentine psychotherapist Carlos Sluski's definition, ${ }^{6}$ a Personal Social Network is the fabric made of those who daily interact with a person and are directly or indirectly accessible to him/her on a regular basis. In terms of disease and care, virtuous circles of protection and mutual maintenance, or vicious circles can be observed between the presence of chronic disease and the negative impact on individual health depending on how the personal network is shaped.

Moffatt et $a l .^{7}$ showed that the probability that the wound heals is greater in patients with larger social networks. The same authors also emphasize that patients with $\mathrm{CW}$ often are well aware that they belong to very limited social networks due to the consequences the presence of ulcers cause. These are both practical consequences - such as limited mobility, reduction of social and often working activities - and perceived ones, e.g. bad smell, that are regarded as a particularly distressing symptom, possibly causing embarrassment and limiting social contact.

Similarly, Carlos Sluski states that a stable, responsive, and active network the individual can rely on protects him/her against disease, impacts on the appropriateness and promptness of decisions to resort to health services, accelerates the healing processes, and in- creases survival. By contrast, the presence of a long-term disease erodes the quality of social interaction in patients and shrinks their network in the long term.

\section{CARLOS SLUSKI'S SOCIAL NETWORK}

When we delve into the construct of Social Network (Red Social), as proposed by Sluski, we realize it consists of the beings we regularly interact with and talk to, and exchange signals that make us real and tangible. In fact, it is this experience that coherently spans over space and time that builds our identity. It is constantly constructed and reconstructed during our lives based on our interaction with others - i.e., relatives, friends and enemies, acquaintances, colleagues, etc. - that is, every people being directly or indirectly accessible to personal contact.

If we assume that individual boundaries are not limited to skin but also include everything that interacts with the subject - being this family, or physical context, etc. then we can consider, by analogy, that the boundaries of individual significant systems are not limited to the nuclear or extended family, but include the whole set of interpersonal ties of a subject, namely family, friends, study and business relations, community inclusion, and social practices. These extend from an inner circle of intimate relationships to an external circle of acquaintances and occasional relations.

The resulting map (Figure 1) can be modelled using four quadrants: i) Family; ii) Friendly relations; iii) School or working relations (classmates/co-workers); iv) Community (e.g., health care) or faith relations and service.

The following three areas are part of the four quadrants: i) an inner circle of intimate relationships, e.g., close family members with whom individuals have daily contact, and close friends; ii) an intermediate circle of personal relationships with a lower degree of commitment, such as the social or business relationships with personal contact but without familiarity, social friends and family relationships with intermediate distance; iii) an outer cir-

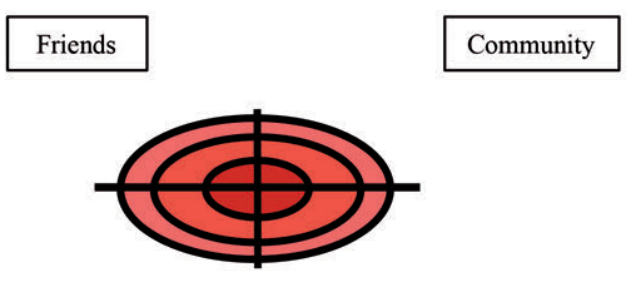

Family

School/Work Relationships

Figure 1. Social network quadrants. 
cle of acquaintances and occasional relationships, e.g., school or work acquaintances, good neighbours, distant relatives or parishioners.

The person's network will be populated differently depending on age (young $v s$. older), financial resources, psychological aspects, native culture, geographical location, status of immigrant or not, etc.

Predictably and understandably, the presence of an illness or, in our case, the presence of skin ulcers affect chances, desires, and the real possibility of creating and maintaining relationships. Mood may lead the patient, and often the people very close to and supportive of to him/her, to take distance from regular relationships, detach themselves from everyday social networks. There is a consequential high risk of triggering a mutual separation process as a response to the illness and to the behaviour of the people who had always been the patient's social network and of his/her family.

Vicious cycles therefore emerge where the presence of chronic illness, or a deficit, or a chronic difficulty of any kind in people negatively affect the social network of the patient, and frequently and more heavily the network that is just outside the nuclear family. In turn, this will negatively impact on the health of the individual or his/her intimate group and both will influence network behaviour, eventually creating a spiral of mutual deterioration.

Based on the low or high number of people in the network, we can effectively predict how much such network can support care therefore the very skin wound healing process.

\section{THE COMMUNITY DIMENSION IN THE CARE MODEL}

Being aware of the impact of an active social network on the healing process is unquestionably of great importance to all stakeholders so that patients and their inner circle of relationships - which often coincides with caregivers - can refrain from the strong and somewhat comprehensible temptation to close themselves off and literally confine themselves within their house walls. Rather, they should be motivated to maintain and possibly expand the network of previously existing relations by relying on all the available resources.

These are, inter alia, multidisciplinary teams that assist patients along the therapeutic process, which carefully consider the relational and community dimension. They can also provide psychological support to encourage people to maintain a network of connections, which has a powerful healing power itself.

In the Chronic Care Model, ${ }^{8}$ adopted by the WHO, ${ }^{9}$ the resources that communities can offer the patients and their family network are high in the agenda. These are: i) Community resources; ii) Health care organizations; iii)
Support to self-care; iv) Organization of the team; v) Decision support; vi) Information systems.

We can include the community dimension and the elements of social network in point ii) together with health care organisations the caring team in point iv), and those who can support decision-making in point $\mathrm{v}$ ).

It is self-evident that Social network and Community dimension are related to other factors as well (see italics numbered list above). Furthermore, 5 out of 7 total factors indicated by the authors of the more recent Expanded Chronic Care $\mathrm{Model}^{10}$ are related to Community. Glasgow et al. ${ }^{11}$ claim that effective prevention of both disease and disability goes beyond the use of clinical services, may include community and foresee collaboration among all involved sectors.

\section{SOME SUGGESTIONS TO SET UP THE NETWORK}

How can we translate the considerations and data we have just shown? We need to conduct a preliminary assessment of the psychosocial conditions of patients and of their families as part of a general assessment of the chronic wound during which we strive to consider the actual clinical practice associated to patients with $\mathrm{CW}$ (and their accompanying family members) and to contribute to both i) increasing the patients' and families' awareness of the importance of maintaining social networks, especially during the healing process, and ii) widening the network itself. It is key to carry out this in-depth assessment during the first visit and continue it during the following visits. The following areas must be covered and evaluated: i) Psychological situation; ii) Individual and family life cycle phase; iii) Socio-economic conditions; iv) Social network; v) Pain perception; vi) Patient timing and disease stage; vii) Expectations.

Research findings reveal that understanding these aspects are everything but irrelevant to health care. Rather, leveraging them as supporting elements to guide therapeutic choices multiplies its effects.

Medical teams may carry out this evaluation, possibly using ad hoc forms that can be converted in a database. In order to realize an immediate and fruitful exchange of information, the most complete and effective practice is in fact conducting a joint general physician/psychologist (and nurse, where possible) examination on the patient and family together during the first or follow-up visits or, depending on the willingness of the patient, in another moment. In this respect, a de facto multidisciplinary team will be able to investigate specific situations, both clinical and socio-relational. This is indispensable to obtain more accurate therapeutic indications and to address patients towards psychological support or psychotherapy, when needed.

In the eco-systemic and relational perspective, proposed by family therapist Froma Walsh, ${ }^{12,13}$ the capabili- 
ties and coping styles of each family are studied in relation both to the individual needs and the wider social systems the family is connected to. Similarly, family difficulties and distress situations should also be viewed as part of a wider and circular context. That is, they may be related to internal stress and complicated by external influence, or vice versa. If a multidisciplinary team choses this model to help patients and their families, the information acquired by the psychologist should become common knowledge to make treatments most effective. Therefore, during the interviews, the following topics will be further investigated: i) The personal meaning of change; ii) The effects of treatments on interpersonal relationships; iii) Availability of a social network; iv) The impact of pain and its treatment on life; v) Expectations.

It has been frequently reported that the burden individuals attribute to the smell of exudate, for example, and its impact on the patient's relational life can vary significantly, depending on age and on the stage of the patient's emotional life. Similarly, the refusal of the unpleasant and unfashionable shape orthopaedic and orthotic footwear to prevent ulcers still have will be different, depending on age, gender, the socio-cultural backgrounds, etc., despite the increasing attention to aesthetics.

On the one hand, the above-mentioned elements are crucial to assess the patient's quality of life. On the other, they are important to make person-specific therapeutic choices that could facilitate compliance. In this respect, knowing if and how the patient relational network shrinks over time, e.g., due to the distance from colleagues if the patient is no longer able to work, or because friendship dwindles if individuals do not feel like or are ashamed to be seen, etc. This is a key factor to effectively assess what kind of support - including practical support - patients have at their disposal and also to predict the effects they may have on the health-related quality of life of patients with $\mathrm{CW}$.

As for the impact of social networks on the healing process, focusing on the team factor is also in order. Consistently with the EWMA position paper ${ }^{5}$ regarding the scientific vocational update activities, the caring staff should be trained to manage relationships of patients. This will enrich personal skills in addition to expanding knowledge and content on the issue to express full care potential of the caring relationship.

In the author's opinion and in the light of several studies conducted over decades in the fields of chronic diseases and oncology, group monitoring and supervision activities are of vital importance, which will enable operators to process all the emotions that treating chronic disease inevitably entails, including non-positive ones, such as frustration and anger.
In dealing with a patient who apparently does not understand the gravity of his/her situation and continues behaving carelessly, physicians and nurses often experience feelings of helplessness and/or anger, generally without acknowledging them. On the other hand, the pragmatic effects of these emotions are well known: they do affect the effectiveness of treatment, also due to the influence they exert on the relationship and the reactions the caring team has with and towards the patient.

Making the National Health System more aware about individual and community economic burden in this sector is an additional element of the action the social network and community in the broadest sense can carry out in favour of the overall $\mathrm{CW}$ treating process. In this respect, in addition to being a practical response to need of families and the public sector to limit expenditure, promoting additional research in this field and focusing attention on this subject, as the Italian Association for Cutaneous Ulcers (AIUC) is doing, is the best signal of a community that cares.

\section{REFERENCES}

1. Chase SK, Melloni M, Savage A. A forever healing: the lived experience of venous ulcer disease. J Vasc Nurs 1997; 15:73-8.

2. Van Korlaar I, Vossen C, Rosendaal FR, et al. Quality of life in venous disease. Thromb Haemost 2003;90:27-35.

3. Hopkins A. Disrupted lives: investigating coping strategies for non-healing leg ulcers. Br J Nurs 2004;13:556-63.

4. Persoon A, Heinen MM, Van der Vleuten CJM, et al. Leg ulcers: a review of their impact on daily life. J Clin Nurs 2004;13: 341-54.

5. European Wound Management Association (EWMA). Position Document: London: MEP Ltd, 2008.

6. Sluski C. La red social: fronteras de la practica sìstemica, Gedisa, 1997.

7. Moffatt C, Vowden P. Hard-to-heal wounds: a holistic approach, European Wound Management Association (EWMA). Position Document. London: MEP Ltd, 2008.

8. Wagner EH. Chronic disease management: what will it take to improve care for chronic illness? Effective Clin Pract 1998;1:2-4.

9. World Health Organization. Innovative care for chronic conditions, Building blocks for action. Geneva: 2002.

10. Barr VJ, Robinson S, Marin-Link B, et al. The expanded chronic care model: an integration of concepts and strategies from population health promotion and the chronic care model. Hosp Q 2003;7:73-82.

11. Glasgow RE, Orleans CT, Wagner EH, et al. Does the chronic care model serve also as a template for improving prevention? Milbank Q 2001;79:579-612.

12. Walsh F. The concept of family resilience: crisis and challenge. Fam Process 1996;35:261-81.

13. Walsh F. Resilienza familiare. Milan: Raffaello Cortina; 2008. 